\title{
Psychosocial variables and quality of life during the COVID-19 lockdown: a correlational study on a convenience sample of young Italians
}

\author{
Anna Lardone ${ }^{\text {Equal first author, } 1}{ }^{\text {, Pierpaolo Sorrentino }}{ }^{\text {Equal first author, } 2}{ }^{2}$, Francesco Giancamilli ${ }^{1}$, Tommaso Palombi ${ }^{1}$, Trevor \\ Simper $^{3}$, Laura Mandolesi $^{4}$, Fabio Lucidi ${ }^{1}$, Andrea Chirico ${ }^{\text {Corresp., } 1}$, Federica Galli ${ }^{\text {Corresp. } 1}$ \\ ${ }^{1}$ Department of Social and Developmental Psychology, Faculty of Medicine and Psychology, University of Roma "La Sapienza", Rome, Italy \\ 2 Institut de Neuroscience des Systemès, Université de Provence (Aix-Marseille I), Marseille, France \\ 3 School of Sports Science, Exercise \& Health., University of Western Australia, Crawley, WA, Australia \\ 4 Department of Humanities, University of Naples Federico II, Napoli, Italy \\ Corresponding Authors: Andrea Chirico, Federica Galli \\ Email address: andrea.chirico@uniroma1.it, federica.galli@uniroma1.it
}

Background In 2020 to limit the spread of Coronavirus (COVID-19), many countries, including Italy, have issued a lengthy quarantine period for the entire population. For this reason lifestyle has changed, bringing inevitable repercussions to the Quality of Life (QoL). The present study aims to identify which psychosocial variables predict behaviors capable of affecting the QoL during the lockdown period, potentially highlighting factors that might promote well-being and health in the Italian population during the epidemic. Methods Between April $27^{\text {th }}, 2020$ and May $11^{\text {th }}, 2020$, we administered a web-survey to a sample of young Italian people (age $M=21.2 ; S D=3.5$; female $=57.7 \%$ of the sample). Employing variance-based structural equation modeling, we attempted to identify whether social connectedness, social support, and loneliness were variables predictive of the QoL of young Italians. We also sought to identify specific psychological factors, such as symbolic threat, realistic threat, and the threat from potentially contaminated objects, was correlated to COVID-19 fear and whether engaging in particular behaviors was likely to improve the QoL. Results Our results suggest that social connectedness and loneliness are significant predictors of QoL, while social support did not have a significant effect on QoL. Furthermore, we observed that symbolic and realistic threats and the threat from potentially contaminated objects are significant and positive predictors of COVID-19 fear. Moreover, COVID-19 fear had significant and positive relationships with the carrying out of specific behaviors, such as creative activities during the isolation period and that this related to affirming individuals' country-specific identity. Finally COVID-19 fear is a significant predictor of behavioral factors related to the adherence to public health advice in line with national guidance regarding the containment of COVID-19 this factor, however, 
did not correlate with QoL. Conclusion Our results suggest the importance of social context and psychological factors to help devise intervention strategies to improve the QoL during lockdown from epidemic events and, in particular, support the importance of promoting social communication and accurate information about the transmission of the virus. 
1 Psychosocial variables and quality of life during the COVID-19 lockdown: a correlational

2 study on a convenience sample of young Italians

4 Anna Lardone $^{1+}$ and Pierpaolo Sorrentino ${ }^{2+}$, Francesco Giancamilli ${ }^{1}$, Tommaso Palombi ${ }^{1}$, 5 Trevor Simper ${ }^{3}$, Laura Mandolesi ${ }^{4}$, Fabio Lucidi $^{1}$, Andrea Chirico ${ }^{1}$, Federica Galli ${ }^{*}$ 6

$7+$ Anna Lardone and Pierpaolo Sorrentino contributed equally to this work

$9{ }^{1}$ Department of Social and Developmental Psychology, Faculty of Medicine and Psychology, 10 University of Roma "La Sapienza", Rome, Italy

112 Institut de Neuroscience des Systemès, Université de Provence (Aix-Marseille I), Marseille, 12 France

$13{ }^{3}$ School of Sports Science, Exercise \& Health, University of Western Australia, Crawley, WA, 14 Australia

$15{ }^{4}$ Department of Humanities, University of Naples Federico II, Napoli, Italy

17 * Corresponding Authors:

18 Andrea Chirico and Federica Galli

19 Via dei Marsi 78, 00185 Rome, Italy

20 andrea.chirico@uniroma1.it

21 federica.galli@uniroma1.it

\section{Abstract}

\section{Background}

25 In 2020 to limit the spread of Coronavirus (COVID-19), many countries, including Italy, have 26 issued a lengthy quarantine period for the entire population. For this reason lifestyle has changed, 27 bringing inevitable repercussions to the Quality of Life (QoL).

28 The present study aims to identify which psychosocial variables predict behaviors capable of 29 affecting the QoL during the lockdown period, potentially highlighting factors that might 30 promote well-being and health in the Italian population during the epidemic.

\section{Methods}

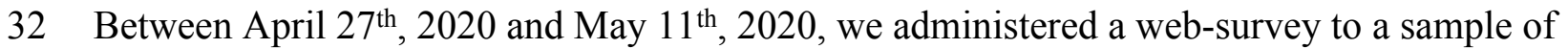
33 young Italian people (age $M=21.2 ; S D=3.5$; female $=57.7 \%$ of the sample). 
34 Employing variance-based structural equation modeling, we attempted to identify whether social connectedness, social support, and loneliness were variables predictive of the QoL of young Italians. We also sought to identify specific psychological factors, such as symbolic threat, realistic threat, and the threat from potentially contaminated objects, was correlated to COVID19 fear and whether engaging in particular behaviors was likely to improve the QoL.

\section{Results}

Our results suggest that social connectedness and loneliness are significant predictors of QoL, while social support did not have a significant effect on QoL. Furthermore, we observed that symbolic and realistic threats and the threat from potentially contaminated objects are significant and positive predictors of COVID-19 fear. Moreover, COVID-19 fear had significant and positive relationships with the carrying out of specific behaviors, such as creative activities during the isolation period and that this related to affirming individuals' country-specific identity. Finally COVID-19 fear is a significant predictor of behavioral factors related to the adherence to public health advice in line with national guidance regarding the containment of COVID-19 this factor, however, did not correlate with QoL.

\section{Conclusion}

Our results suggest the importance of social context and psychological factors to help devise intervention strategies to improve the QoL during lockdown from epidemic events and, in particular, support the importance of promoting social communication and accurate information about the transmission of the virus.

Keywords: Coronavirus, Quarantine, Lockdown, Quality of Life, Variance-Based Structural Equation Modeling, COVID-19 web-survey, pandemic, epidemic, Fear for COVID-19.

\section{Introduction}

During the last months of 2019 in Wuhan (China), the rapid spread of a pathogenic event was attributed to a new virus: Coronavirus (SARS-CoV-2 or COVID-19), belonging to the Coronaviridae family (Guo et al., 2020). The coronavirus epidemic soon became a global problem: on August 1 ${ }^{\text {st }}, 2020$, the World Health Organization (WHO) confirmed that COVID-19 had caused over 674,291 deaths. Given the virus's novelty, the world health system has had difficulty identifying effective treatment and a viable vaccine. One of the most effective restraint 
65 measures to reduce the spread of the infection has been the imposition of social distancing 66 (Hellewell et al., 2020). In Italy, a country significantly affected, the national government

67 imposed a lockdown that began on March $10^{\text {th }} 2020$ and, after further extensions, ended on May

$683^{\text {rd }} 2020$ for a total of 54 days, prohibiting all non-essential business activities and banning all

69 movements of people nationwide.

70 Besides the COVID-19 pandemic, the world has previously faced a number of epidemics,

71 previous literature provides an overview of the effects of these events on the population.

72 For example, epidemics and relative restraint measures can have potentially deleterious effects

73 on people's mental health (Ma et al., 2020; Zhang \& Ma, 2020; Zhang Y \& Ma Z, 2020). A recent review considered the epidemics of the last twenty years, including SARS, Ebola, the H1N1 flu pandemic, Middle East respiratory syndrome, and equine flu and reported adverse psychological effects due to quarantine with an increase in psychological distress. It has been reported that these consequences can be long-lasting (Brooks et al., 2020). Among the consequences mentioned above, recorded in previous epidemic events, there was a worsening of the perception of the quality of life (QoL; Hui et al., 2005; Van Bortel et al., 2016). QoL relates to how an individual evaluates the 'goodness' of multiple aspects of his/her life. These self-assessments are comprised of: one's emotional reactions to life occurrences, disposition, sense of life fulfilment, and satisfaction with work and personal relationships (Diener et al., 1999). Scientific literature dealing with the predictors of QoL also reports the importance of several social factors. Among these are social connectedness, the perception of social support, and the feeling of loneliness (e.g., Sherbourne \& Stewart, 1991; Brown, Hoye \& Nicholson, 2012).

87 Regarding social connectedness (defined as feelings of interpersonal closeness with others; Lee 88 \& Robbins, 1995) in the scientific literature, there is a consensus that considers this factor as a basic psychological need and that its fulfilment brings about an improvement in QoL. These findings have been shown, in samples of young people via different data analytic methods, such

91 as ANOVAs (e.g., Gillison, Standage \& Skevington, 2008), network analyses (e.g., Kuczynski, 92 Kanter \& Robinaugh, 2020), and using Structural Equation Models (SEM; Jose \& Lim, 2014), to 93 cite few. Considering the social restraints imposed during COVID-19, recent research has 94 demonstrated that university students report significantly lower social connectedness levels than 
95 the levels reported prior to the pandemic. Moreover, social connectedness was positively

96 associated with individuals' sense of well-being (Folk et al., 2020).

97 The second construct we propose (i.e., social support) is defined as the degree to which one

98 perceives emotional and instrumental support in personal relationships (Ozbay et al., 2007).

99 Perceived social support could be considered a beneficial factor with the potential to reduce the 100 negative effects of stress and facilitate adaptation after traumatic experiences (Özmete \& Pak,

101 2020), subsequently improving QoL (Xu \& Ou, 2014). The relationship between social support

102 and QoL has been widely investigated in systematic reviews and meta-analyses considering

103 different target populations, such as lung cancer patients (Luszczynska et al., 2013), stroke

104 survivors' (Kruithof et al., 2013), family caregivers (Sajadi, Ebadi \& Moradian, 2017), and

105 children and adolescents (Chu, Saucier \& Hafner, 2010). Moreover, regarding specific contexts

106 that could have a worsening impact on perceived social support (e.g., social isolation, quarantine

107 due to a pandemic), a recent study on healthcare professionals highlighted that perceived social

108 support was positively correlated with QoL during the COVID-19 outbreak (Vafaei et al., 2020).

109 Regarding our third proposed factor, loneliness (defined as the perception of discrepancy

110 between actual and desired levels of social relationships; Sherbourne \& Stewart, 1991; Valtorta

111 \& Hanratty, 2012) the literature showed that loneliness has a direct association with QoL,

112 demonstrating that lonely individuals have a poor level of QoL (Cacioppo et al., 2006; Cacioppo,

113 Hawkley \& Thisted, 2010). Indeed, social isolation is a factor that could increase loneliness

114 (Lim, Eres \& Vasan, 2020). During the COVID-19 outbreak in Italy, the young population has

115 experienced home-quarantine and the closing of many normal activities such as bars and cafes,

116 meetings in public and the closing of schools, directly limiting the number of social interactions

117 amongst young people. A recent investigation demonstrated that, during COVID-19 lockdown,

118 loneliness was associated with depression, emotion regulation difficulty, poor sleep quality,

119 stress (Groarke Id et al., 2020; Probst, Budimir \& Pieh, 2020), and depression (Probst, Budimir

$120 \&$ Pieh, 2020). COVID-19 preventive measures impact not only on everyday life but also social

121 activities and personal relationships. Indeed, a broad part of literature considers the role of

122 concerns (i.e., perceived threats and overestimation of contamination) and fear related to

123 epidemic events (e.g., Abramowitz \& Blakey, 2020) as predictors or mediators of QoL indicators

124 (Kachanoff et al., 2020; Satici et al., 2020a,b). Moreover, fear related to infection is also related 
125 to public health compliance behaviors (Harper et al., 2020), and social identity affirming 126 behaviors.

127 The literature suggests a relationship between COVID-19 outbreak and the concerns related to

128 the feeling of threat experienced during the pandemic. More specifically, Kachanoff and

129 colleagues (2020) conceptualized two different cognitive evaluations of the threat: the realistic

130 threat, i.e., the fear of the physical and economic consequences of contagion (Kachanoff et al.,

131 2020), and the symbolic threat, that is related to the possible negative consequences of an

132 epidemic on one's national and cultural identity (Tajfel \& Turner, 1979; Stephan, Ybarra \&

133 Morrison, 2009).

134 Considering the COVID-19 pandemic context, it might be useful to evaluate the role of

135 likelihood and severity overestimation of contamination, since this construct has a relevant

136 impact on the origin, development, and maintenance of fear about contracting the disease (e.g.,

137 Rachman, 2004; Abramowitz \& Blakey, 2020). Literature has generally shown that a higher

138 level of the perceived threat and the overestimation of the likelihood and severity of

139 contamination are associated with a higher level of ill-related fear (Blakey et al., 2015;

140 Kachanoff et al., 2020). Accordingly, it could be reasonable to consider as precursors of fear for

141 diseases not only the perceived threats (i.e., realistic, and symbolic) but also the overestimation

142 of the likelihood of contamination.

143 In the current pandemic fear of COVID-19 has negatively affected mental well-being and life

144 satisfaction (Satici et al., 2020a,b). Despite these negative implications, fear can also encourage

145 people to reduce health-threatening behaviors. A recent study by Harper and colleagues

146 highlighted the functional role of fear of COVID-19 in predicting adaptive behaviors following

147 public health recommendations (e.g., washing hands and observing social distancing; Harper et

148 al., 2020). In their results, the authors showed that enacting these kinds of behaviors could

149 partially improve QoL, and these findings have also been confirmed by other investigators (e.g.,

150 Wang et al., 2020). In order to overcome perceived threats and contagion fear in a social

151 distancing context, people tried to cope by carrying out behaviors that affirm social (e.g.,

152 interacting virtually online with cultural groups sharing media about life before COVID-19) and

153 national identity (e.g., cooking typical recipes; Jaspal \& Nerlich, 2020; Kachanoff et al., 2020).

154 These behaviors may well act as strategies which help to cope with the fear of contagion,

155 transiently enhancing well-being and therefore QoL (Karwowski et al., 2020). 
156 In light of the above, the present study aims to identify which psychosocial variables could

157 predict behaviors capable of affecting the QoL during the lockdown period and to understanding

158 relevant factors that could promote well-being and health in the Italian population during the

159 pandemic. Therefore, we hypothesized that the data would fit with the proposed model (figure

160 1). Specifically, our principal hypotheses are that the social constructs (i.e., social connectedness

161 and social support) will positively predict QoL and that loneliness will have a negative effect on

162 QoL. Moreover, we also suggest that perceived threats (i.e., realistic and symbolic) and the

163 overestimation of threat from potentially contaminated objects will both predict the fear of

164 COVID-19 positively. We also hypothesize that fear of COVID-19 will have positive effects on

165 support for public health initiatives and the social identity affirming behaviors. Also, we propose

166 that QoL will be positively predicted by support for public health initiatives and social identity

167 affirming behaviors. Finally, we posed a secondary set of hypotheses regarding the other direct

168 and indirect relationships between variables (see table 1).

170 Methods

171 Participants and procedure

172 We administered an online survey, written in the Italian language, through Qualtrics software

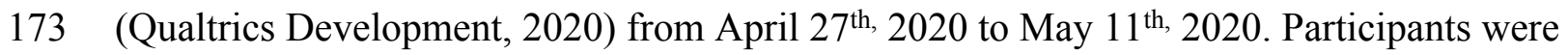

174 recruited using an online survey link, posted on the University course webpage (convenience

175 sampling). Before filling the survey, participants were informed about the general aim of the

176 research and their rights to anonymity. Collection of the written informed consent was performed

177 through Qualtrics. This platform permits the participants to pause the survey filling and resume it

178 at will. However, the time needed to complete the survey took approximately 25 minutes.

179 Collected data were coded and processed anonymously. The Ethics Committee of the

180 Department of Humanities of the University of Naples "Federico II" approved the study (n.

181 13/2020). Participants who completed the web survey were 213 young adults, (age $M=21.2 ; S D$

$182=3.5$; female $=57.7 \%$ of the sample). The characteristics of the sample are described in table 2. 183

\section{Measures}

185 The web-survey included social and psychological measures related to COVID-19 and QoL

186 during the pandemic period. As the original versions of the scales were in English, all the scales 
187 were translated from English to Italian by two English-Italian bilinguals, using standardized back

188 translation procedures. Given the strict timing due for the ongoing emergency, we only were able 189 to test for content and face validity. The face validity was tested by 10 students (aged from 18 to

190 26) who evaluated the questionnaires through a think-aloud procedure (Drennan, 2003). The

191 measures included in the web-survey were focused on the following key variables:

192 Perceived social connectedness was measured using the Social Connectedness Scale (SCS; Lee 193 and Robbins, 1995), it is an 8-item self-report measure (item example: "I feel disconnected from 194 the world around $\left.m e^{\prime \prime}\right)$. Participants rated each item on a 6-point Likert scale ranging from 1

195 (Strongly Agree) to 6 (Strongly Disagree). The scale measures the emotional distance perceived

196 between oneself and others, focusing on three aspects of belongingness: connectedness,

197 companionship, and affiliation.

198 Social support was measured using the Medical Outcomes Study Social Support Survey (MOS;

199 Sherbourne and Stewart, 1991), it is a 19-item self-report measure (item example: "Someone you 200 can count on to listen to you when you need to talk"). Participants rated each item on a 5-point

201 Likert scale ranging from 1 (None of the time) to 5 (All of the time). This scale assesses

202 emotional/informational, structural, affectionate, and positive social interaction.

203 Loneliness was measured using the University of California Los Angeles (UCLA) Loneliness

204 Scale (UCLALS; Russell, 1996), it is a 20-item self-report measure of loneliness (item example:

205 "How often do you feel alone?"). Participants rated each item on a 4-point Likert scale ranging

206 from 1 (Never) to 4 (Always). The scale measures the degree of perceived loneliness of the 207 participant.

208 Quality of life was measured using the World Health Organization Quality of Life - BREF

209 (WHOQOL - BREF; World Health Organization, 1996); it is a 26-item self-report measure. This

210 scale measures quality of life, including four domains: physical health (item example: "Do you

211 have enough energy for everyday life?"), psychological health (item example: "How much do

212 you enjoy life?"), social relationships (item example: "How satisfied are you with your personal

213 relationships?"), and environment (item example: "How safe do you feel in your daily life").

214 Participants rated each item on a 5-point Likert scale ranging from 1 (Very dissatisfied/Not at

215 all/Very poor/Never) to 5 (Very satisfied/An extreme amount/Extremely/Completely/Very

216 Well/Always). For the present investigation the QoL mean score was computed by combining the 
217 four domains' scores, as conducted in other studies (Kuczynski, Kanter \& Robinaugh, 2020). We

218 used the Italian validated version (World Health Organization, 1996).

219 COVID-19 threat was measured using an adapted version of the Integrated COVID-19 Threat

220 Scale (Kachanoff et al., 2020). The scale is a 10-item self-report measure that assesses the

221 experience of symbolic and realistic threat of COVID-19 towards the American culture and

222 context. All items were framed with the opening: "How much of a threat, if any, is the

223 coronavirus outbreak to...". Two factors compose this scale. The first is "Realistic COVID-19

224 Threat", measured by 5 items (e.g., "Your personal health"), that refers to the perception of a

225 concrete risk to an individual's (or group's) physical health and economic well-being due to the

226 pandemic. The second factor is "Symbolic COVID-19 Threat" measured by 5 items (e.g.,

227 "American values and tradition") that assesses the perception of danger for social identity caused

228 by the methods used to prevent the spread of the COVID-19 virus (e.g., social distancing,

229 lockdown). Participants rated each item on a 4-point Likert scale ranging from 1 (Not a Threat)

230 to 4 (Major Threat).

231 We adapted the Integrated COVID-19 Threat Scale to the Italian culture substituting "American"

232 with "Italian" in each item where it was referred (e.g., "Italian values and tradition").

233 Overestimation of threat from potentially contaminated objects was measured using the

234 Contamination Cognition Scale (CCS; Deacon \& Olatunji, 2007). This scale measures the

235 individual's perception of the likelihood of contamination; it comprises a list of 13 everyday

236 objects often associated with germs (e.g., door handles and toilet seats). Participants were asked

237 to rate the likelihood and severity of contamination if they were to touch each object. Ratings

238 were given on a 0-100 scale, where 0 "Not at all likely", 50 "Moderately likely", and 100

239 "Extremely likely" (likelihood ratings); 0 "Not at all bad", 50 "Moderately bad" and 100

240 "Extremely bad" (severity ratings).

241 Fear for COVID-19 was measured using an adapted version of the Ebola Fear Inventory (EFI;

242 Blakey et al., 2015) and Swine Flu Inventory (SFI; Wheaton et al., 2012). The adapted version

243 that we titled: COVID Fear Inventory (CFI) is a 9-item self-report measure (item example: "To

244 what extent are you concerned about COVID-19?"). Participants rated each item on a 5-point

245 Likert scale ranging from 1 (Not at all) to 5 (Very much). The items assess participants' concern

246 about the spread of COVID-19, the perceived probability of contracting the virus, the use of

247 safety behaviors, and the degree of exposure to information related to COVID-19. The

Peer] reviewing PDF | (2020:08:51872:2:0:NEW 25 Nov 2020) 
248 adaptation consisted of substituting "Ebola" with "COVID-19" in each item where it was 249 referred.

250 Social identity affirming behaviors during isolation were measured using an adapted version of 251 the Social Identity Affirming Behaviors in Isolation scale (SIABI; Kachanoff et al., 2020). This 252 scale is a 5-items self-report measure (item example: "I share things with my friends and family 253 on the phone or through social media that remind us of what life was like in Italy before COVID254 19"). Participants rated each item on a 5-point Likert scale ranging from 1 (Not at all) to 5 255 (Always). This scale assesses the engagement in creative behaviors during the isolation to affirm 256 one's Country-specific identity (item example: "I engage in behaviors that I associate with 257 Italian identity, e.g., I cook foods that make me feel Italian"). We adapted the Social Identity 258 Affirming Behaviors in Isolation scale to the Italian Country substituting "American" with 259 "Italian" in each item where it was referred.

260 Support for Public Health Initiatives was measured using the Support for Public Health 261 Initiatives to Reduce Spread of COVID-19 scale (RSC; Kachanoff et al., 2020), a 4-item self262 report tool (item example "Right now the most important thing we can do is take all measures 263 possible to stop the spread of COVID-19"). Participants rated each item on a 7-point Likert scale 264 ranging from 1 (Strongly disagree) to 7 (Strongly agree). This scale assesses the degree of 265 agreement and adherence to public health initiatives (such as social distancing and hand-washing 266 for examples).

267

\section{Data Analysis}

269 The statistical significance for all the performed analysis were set at $\alpha=.05$. Descriptive 270 analyses were calculated to describe the sample characteristics (i.e., sociodemographic). We 271 tested the hypothesized model using variance-based structural equation modeling (VB-SEM) 272 through the WarpPLS v 7.0 software (Kock, 2020). The VB-SEM computed by Warp PLS is a 273 partial least squares-based structural equation modeling (PLS-SEM).

274 Through VB-SEM, it is possible to test two models: a measurement model (the relationship 275 across measured and latent variables) and a structural model (the relationship across latent 276 variables; Hair Jr et al., 2016). The measurement model is tested based on criteria associated 277 with the reliability, the convergent and discriminant validity, through the assessing of composite 278 score reliability $(>.70)$, Cronbach's alpha $(>.70)$ the average variance extracted in each factor 
279 (AVE; >.50) and the square root of the average variance extracted (square root of AVE $>$ each

280 factor-to-factor correlation; Fornell \& Larcker, 1981; Barclay, Higgins \& Thompson, 1995;

281 Chin, 1998; Henseler, Ringle \& Sinkovics, 2009). Regarding the structural model, indices were

282 calculated to assess the goodness-of-fit: the Tenenhaus Goodness-of-fit index (Tenenhaus GoF:

283 small $\geq 0.1$, medium $\geq 0.25$, large $\geq 0.36$ ), the average variance inflation factor (AVIF $<5$ as

284 acceptable; $\leq 3.30$ as ideally) and the average full collinearity (AFVIF; $<5$ as acceptable; $\leq 3.30$

285 as ideally), the average path coefficient (APC; $p<.05$ ) and adjusted average $\mathrm{R}^{2}$ (AARS; $p<.05$;

286 Tenenhaus et al., 2005; Wetzels et al., 2009). The latent variables' relationship was showed as

287 standardized path coefficients $(\beta)$ and their relative $p$-values $(p)$. These relationships indicators

288 are calculated through a resampling method by-default provided by WarpPLS (i.e., "Stable3")

289 that permits a reasonable estimation of standard errors (for a full description, see Kock, 2020) to

290 avoid potential issues regarding the distortion of relationship findings. To test for hypothesized

291 mediation pathways in our model, we employed the estimation of indirect effects described by

292 Kock (2014) and Kock \& Gaskins (2014).

293 Compared to covariance-based structural equation modeling (CB-SEM), a particular advantage

294 of VB-SEM is the estimation of fit indices, and parameters estimate using a partial least-squares

295 algorithm (PLS). The PLS estimator allows, compared to CB-SEM, to avoid restrictions due to

296 assumptions related to the sampling distribution without being affecting by small sample size

297 (Reinartz, Haenlein \& Henseler, 2009). In any way, findings provided by PLS-SEM are

298 described as eligible in psychological research, comparable to CB-SEM (Willaby et al., 2015;

299 Hair Jr et al., 2016).

300

301 Results

302 Measurement Model

303 Findings related to the reliability, convergent, and discriminant validity indices are presented in

304 table 3. Overall, results showed acceptable reliability for the measurement model, as composite

305 score reliability and Cronbach's alpha are above the mentioned threshold, except for CFI and

306 RSC. Indeed, the Cronbach's alpha of these two latent variables was below the threshold of .70,

307 whereas the composite score reliability of both variables was above .70. The unequal factor

308 loadings of indicators probably caused CFI and RSC differences between Cronbach's alpha and 309 composite score reliability (see Zinbarg et al., 2005; Raykov, 2012), suggesting that composite 
310 reliability could be a better estimator for the reliability of these variables. Regarding validities,

311 all items loaded on their respective latent variable in a significant way $(\mathrm{p}<0.001)$. AVE results

312 showed that UCLALS, CCS, CFI, and SIABI were below the acceptable threshold $(.43, .45, .35$,

313.49 , respectively); nevertheless, given the reliability indices above .70 , the convergent validity of

314 these variables was considered adequate (Fornell \& Larcker, 1981). At last, the measurement

315 model exhibited an acceptable discriminant validity, as the square root of the AVE for each

316 latent variable exceeded the correlation between all the variables.

\section{Structural Model}

318 Regarding the structural model, indices were calculated to assess the goodness-of-fit. Overall,

319 findings exhibited a good model fit (Tenenhaus $\mathrm{GoF}=.36$; $\mathrm{AVIF}=1.25 ; \mathrm{AFVIF}=1.52 ; \mathrm{APC}=$

$320.15, p=.007 ;$ AARS $=.26 \mathrm{p}<.001)$.

321 The hypothesized model showed that the social connectedness, as predicted $\left(\mathrm{H}_{1 \mathrm{a}}\right)$, positively

322 affected QoL. Moreover, loneliness was a significant and negative predictor of QoL $\left(\mathrm{H}_{1 \mathrm{c}}\right)$.

323 Contrary to our hypotheses, social support did not have a significant effect on QoL $\left(\mathrm{H}_{1 b}\right)$.

324 Findings regarding symbolic threat $\left(\mathrm{H}_{2 \mathrm{a}}\right)$, realistic threat $\left(\mathrm{H}_{2 \mathrm{~b}}\right)$, and the overestimation of threat

325 from potentially contaminated objects $\left(\mathrm{H}_{2 \mathrm{c}}\right)$ confirmed our hypothesis, as these variables were

326 significant and positive predictors of fear for COVID-19. In turn, as assumed, this latter factor

327 had significant and positive relationships with social identity affirming behaviors during

328 isolation $\left(\mathrm{H}_{3 \mathrm{a}}\right)$ and support for public health initiatives $\left(\mathrm{H}_{3 \mathrm{~b}}\right)$.

329 Furthermore, in line with our hypotheses, the model exhibited the significant and positive effect

330 of social identity affirming behaviors during isolation on QoL $\left(\mathrm{H}_{4 \mathrm{a}}\right)$. Conversely, support for

331 public health initiatives did not have a significant effect on QoL $\left(\mathrm{H}_{4 \mathrm{~b}}\right)$. Regarding the positive

332 effect of symbolic threat $\left(\mathrm{H}_{5 \mathrm{a}}\right)$, realistic threat $\left(\mathrm{H}_{5 \mathrm{~b}}\right)$, and the overestimation of threat from

333 potentially contaminated objects $\left(\mathrm{H}_{5 \mathrm{c}}\right)$ on social identity affirming behaviors during isolation,

334 only the realistic threat did not have a significant effect on this factor. The findings related to the

335 effects of the symbolic threat $\left(\mathrm{H}_{6 \mathrm{a}}\right)$ and the overestimation of threat from potentially

336 contaminated objects $\left(\mathrm{H}_{6 c}\right)$ on support for public health initiatives showed a significant and

337 negative effect of symbolic threat and a not significant effect of the overestimation of threat on

338 support for public health initiatives. In contrast, the realistic threat had a positive and significant

339 effect on this variable $\left(\mathrm{H}_{6 \mathrm{~b}}\right)$. Considering the mediation role of fear for COVID-19, the

340 hypothesis confirmed by our data is a partial mediation role of this factor for the relationship 
341 between realistic threat and social identity affirming behaviors during isolation $\left(\mathrm{H}_{7 \mathrm{~b}}\right.$; the indirect

342 effect considering fear for COVID-19 was $\beta=.113 \mathrm{p}<.01$ ), and its total mediation role in the

343 relationship between realistic threat and support for public health initiatives $\left(\mathrm{H}_{8 \mathrm{~b}}\right.$; the indirect

344 effect considering fear for COVID-19 was $\beta=.133, \mathrm{p}<.01)$.

345 Meanwhile, fear for COVID-19 was not a mediator for the effects of symbolic threat on social

346 identity affirming behaviors in isolation $\left(\mathrm{H}_{7 \mathrm{a}}\right)$ and on support for public health initiatives $\left(\mathrm{H}_{8 \mathrm{a}}\right)$.

347 Again, fear for COVID-19 did not act as a mediator for what concerns the other factors $\left(\mathrm{H}_{7 \mathrm{c}}\right.$ and

$348 \mathrm{H}_{8 \mathrm{c}}$ ). Finally, we controlled for the direct effects of QoL predictors on fear for COVID-19, and

349 we also controlled for fear for COVID-19 predictors on QoL (table 4).

350 The standardized path coefficients $(\beta)$ and their relative $p$-values $(p)$ are shown in figure 2 . The

351 variance explained by the model for QoL was .34.

352

353 Discussion

354 The present study identifies social and psychological factors related to the QoL during the Italian

355 COVID-19 lockdown period. Employing a structural equation model, we tested if social

356 connectedness, social support, and loneliness were direct predictors of QoL and if specific

357 psychological factors, such as concerns related to COVID-19 (i.e., perceived threats and the

358 overestimation of contagion by objects) were correlated to the COVID-19 fear. Finally, we

359 hypothesized that fear of COVID-19 would predict behavioral factors able to improve the QoL,

360 such as support for public health initiatives to reduce the spread of contagion and social identity

361 affirming behaviors during isolation.

362 In particular, social connectedness was a direct predictor of QoL and loneliness was a negative

363 predictor. Contrary to our hypotheses, social support was not a significant predictor (see figure

364 2). These findings highlight the human need to connect socially and reduce the discrepancy

365 between actual and desired social relationship levels. These results are in line with literature

366 dealing with the effect of social factors on QoL both within the context of a pandemic (e.g.,

367 Nitschke et al., 2020) and those that are not (e.g., Reyes et al., 2020).

368 Social connectedness and a lack of loneliness seem to be significantly impaired, especially

369 during lockdown periods in epidemic events (e.g., Jose \& Lim, 2014; Kuczynski, Kanter \&

370 Robinaugh, 2020). Indeed, it is important to consider the evidence that individuals who perceive

371 themselves as lonely or not socially connected have a lower QoL than more socially connected 
372 people. Furthermore, lonely people also have an increased risk of developing pathological

373 conditions such as cardiovascular disease (Caspi et al., 2006; Hawkley \& Cacioppo, 2010;

374 Leigh-Hunt et al., 2017), inflammatory diseases (Cole et al., 2007), depressive symptoms (Jose

$375 \&$ Lim, 2014), diminished executive control (Cacioppo et al., 2000), and negative alterations to

376 their immunological health (Pressman et al., 2005; Rico-Uribe et al., 2018).

377 Moreover, it is interesting to note that social support did not have a significant effect on QoL.

378 However, literature reports social support as an essential resource for coping with different

379 stressors (Warner et al., 2015), including those within a pandemic context (Alyami et al., 2020).

380 From a psychometric point of view, this finding could be explained by the so-called ceiling

381 effect (Michalos, 2014), given a high mean score, low variability of the sample (social support,

382 mean: 4.2 on a 5-point scale; SD: 0.7 ), together with a relatively low number of participants

383 ( $\mathrm{N}=213)$. This result is not entirely counterintuitive because our sample is composed mainly of

384 young adults living with their parents $(\mathrm{n}=197)$, from whom they probably receive adequate

385 social support. Furthermore, an alternative explanation for this finding could be related to the

386 role of gender. Indeed, it has been documented that social support appears to be more important

387 for women than men (Verger et al., 2009). Due to the relatively small number of participants in

388 our study, we performed analysis without considering the possible effect of gender on QoL;

389 therefore, this could have been an additional factor.

390 Concerning our hypothesized model's psychological factors, we observed that symbolic threat,

391 realistic threat, and the overestimation of the likelihood/severity of contamination were

392 significant and positive predictors of the COVID-19 fear. Our results about the two threats (i.e.,

393 symbolic and realistic) are in line with the original conceptualization of these variables described

394 as cognitive evaluations of COVID-19 fear (Kachanoff et al., 2020). At the same time, it is also

395 not surprising that concerns regarding the likelihood/severity of contamination significantly

396 predicted the fear for COVID-19. This pattern might be explained considering the role of the

397 media during the actual pandemic. Media has a high coverage for COVID-19 news, being

398 particularly intrusive about this disease's contagion modalities, leading people to overestimate

399 the likelihood/severity of being infected, as already reported by Blakey and colleagues (2015)

400 during the Ebola spread.

401 Moreover COVID-19 fear had significant and positive relationships with specific behavioral

402 factors, such as public health initiatives to reduce the spread of contagion and social identity 
403 affirming behaviors during isolation. These results are also in line with previous literature, 404 suggesting the fear of a COVID-19 pandemic outbreak is positively related to behavioral factors 405 related to public health advice compliance (Harper et al., 2020). In particular, as reported in a 406 recent review (see Perkins \& Corr, 2014), negative feelings and emotions may trigger more 407 adaptive and protective behaviors (i.e., public health-compliant behavior change), with a 408 personal safety function.

409 Concerning the role of COVID-19 fear on social identity affirming behaviors, Kanekar \& 410 Sharma (2020) suggested that the commitment to creative activities (e.g., cooking, trying new 411 ways to connect with others) during the lockdown period might help to improve individual's 412 coping strategies and, help to promote mental well-being. Gerhold (2020) suggested that his 413 sample of the German population acted mainly on problem-centered coping strategies (e.g., 414 "doing something completely new that I would never have done in other circumstances") in 415 response to the increasingly restrictive measures imposed by the government. In line with these 416 results, our model shows that young Italians engaged in similar creative behaviors, focused on 417 the affirmation of Italian culture, to overcome COVID-19 fear, which has positively impacted on 418 the maintenance of their well-being.

419 Concerning the role of COVID-19 fear as a mediator in our model, our results showed that fear 420 acts as a partial moderator for the relationship between realistic threat and behavioral factors 421 related to support for public health initiatives. Instead, findings of the mediation role of COVID-

42219 fear on the relationship between realistic threat and social identity affirming behaviors during 423 isolation exhibited a total mediation pathway. These two mediation pathways are the only two 424 which were significant in our model.

425 Accordingly, it is possible to deduce that people may significantly benefit from engaging in 426 some form of social identity affirming behavior as a coping strategy. Also, our findings showed 427 that people strongly supported the government's restrictive policy to contain the COVID-19 428 outbreak not only because of the effect of the COVID-19 fear but also due to the role of the 429 perception of the threat related to possible detrimental consequences on their health and 430 economic well-being.

431 Our model also showed a positive direct effect of realistic threat on behavioral factors related to 432 public health initiatives intended to reduce the spread of COVID-19 and, at the same time, our 
433 model did not suggest a significant effect on social identity affirming behaviors, in line with the 434 results showed by Kachanoff and colleagues (2020).

435 Not surprisingly, the symbolic threat had a positive effect on social identity affirming behaviors 436 and a negative effect on behavioral factors related to support for government health 437 recommendations which is the same as the findings from Kachanoff and colleagues (2020). 438 Given that symbolic threat refers to the perception of danger for social identity caused, for 439 example, by social distancing it seems logical that people might not support measures that 440 potentially impact negatively on their social identity. This threat to social identity may well 441 encourage people to find new and creative ways to connect socially (e.g., singing to their 442 neighbors on the balcony).

443 Regarding the direct effects of the overestimation of contagion on the behavioral factors, instead, 444 we found that this overestimation directly affected social identity affirming behaviors and not 445 behavioral factors related to health-compliance recommendations. This latter result is not in line 446 with the one exhibited by Blakey and colleagues (2015). We could explain this result from a 447 statistical point of view. The overestimation of contagion act as a suppressor variable for the 448 mediated relationship between threats and behavior related to health-compliance 449 recommendations (MacKinnon, Krull \& Lockwood, 2000). Indeed, we observed that if we 450 statistically control for the overestimation of contagion, there is an increase of the effects of 451 threats on fear of COVID-19 (without controlling: $\beta_{\text {symbolic }}=.087, p=.10$ and $\beta_{\text {realistic }}=.365, p<$ 452.001 vs controlling: $\beta_{\text {symbolic }}=.100, p=.07$ and $\left.\beta_{\text {realistic }}=.421, p<.001\right)$. Moreover, if we 453 removed realistic and symbolic threats from the model, the fear for COVID-19 acts as a total 454 mediator in the relationship between the overestimation of contagion and safety behaviors 455 (indirect effect: $\beta=.093, p=.026$; direct effect: $\beta=.07, p=.17$ ). It is interesting to note that only 456 social identity affirming behaviours had a significant impact on QoL. In fact, as previously 457 discussed, the involvement in creative behaviors could have a positive impact on mental health 458 and QoL during a lockdown period (Kanekar \& Sharma, 2020; Karwowski et al., 2020).

459 Finally, regarding the non-significant effect of behaviors related to health-compliance public 460 health recommendations on QoL, Harper and colleagues (2020) described similar results, 461 showing a non-significant relationship between these behaviors and QoL. We speculate, 462 meanwhile the social identity affirming behaviors can be considered as coping strategies that are 463 implemented by the young Italian population to maintain well-being routines, especially during 
464 isolation, the behaviors related to public health initiatives to reduce the spread of COVID-19 465 might not have a significant impact on QoL, because these measures (e.g., social distancing, 466 washing hands) are just limited to avoid COVID-19 contagion, and not to improve individual's 467 well-being and not necessarily their QoL.

\section{Strengths, limitations, and future directions}

469 This study is the first on young adults during the COVID-19 pandemic that evaluates the role of different social variables and psychological factors as QoL predictors. The study is also unique

471 for the data collection timing (i.e., during a COVID-19 lockdown period). These strengths notwithstanding, the present research has a few limitations. The sample is composed of young Italian adults recruited through convenience sampling. For this reason, we cannot affirm that the sample was representative of the entire young Italian population. Moreover, we cannot generalize our results to other age groups and countries. It is conceivable that children, adolescents, adults, and older adults, of our own and other countries have responded differently to the imposition of lockdown and social distancing. Therefore, it is urgent in the near future to devise a broader research design that involves the collaboration of researchers from as many countries as possible and which evaluates the responses of other sections of the population. It may be beneficial to analyze these psychosocial factors in specific sections of the populations, (e.g. children, preschool, and school). The results obtained would make it possible to develop actions also at the school level, where the use of distance learning is still much debated. A further study analyzing QoL-related factors in a sample of children using digital platforms might prove to be useful for implementing this teaching method in the near future. In addition to children, it would also be useful to study psychosocial factors related to QoL in the elderly, who appear to be the category that is most likely to be affected negatively by COVID-19 (i.e., high death rates and severity of the outcome even when they survive). Again, knowledge of the factors that significantly improve QoL could prove useful for evaluating the effects of applying specific advice/support during lockdowns for this segment of our population. Regarding the development of our survey, the strict timing due for the ongoing emergency, meant we only could adopt a standardized back translation and face validity procedure, providing

492 for content and face validity, without considering other types of validities (e.g., criterion and 493 construct validities). Future studies should test the psychometric validity of the scales used in 
494 this research to produce a complete, valid questionnaire for COVID-19 psychosocial related 495 factors.

496 In conclusion, our results suggest the importance of analyzing both social context and

497 psychological factors in order to devise intervention strategies to improve the QoL of young

498 Italians during COVID-19 lockdown. Programs for young people should promote social

499 communication and accurate information about the transmission methods of COVID-19. Our

500 results underline how much human relationships are fundamental for maintaining physical and 501 psychological well-being.

502 
503

504

505

506

507

508

509

510

511

512

513

514

515

516

517

518

519

520

521

522

523

524

525

526

527

528

\section{References}

Abramowitz JS, Blakey SM. 2020. Overestimation of threat. In: Clinical handbook of fear and anxiety: Maintenance processes and treatment mechanisms. Washington, DC, US: American Psychological Association, 7-25. DOI: 10.1037/0000150-001.

Alyami M, De Albuquerque JV, Krägeloh CU, Alyami H, Henning MA. 2020. Effects of Fear of COVID-19 on Mental Well-Being and Quality of Life: A path analysis.

Barclay D, Higgins C, Thompson R. 1995. The Partial Last Squares (PLS) approach to causal modelling, personal computer adoption and use as an illustration. Technology Studies 2:285-309.

Blakey SM, Reuman L, Jacoby RJ, Abramowitz JS. 2015. Tracing "Fearbola": Psychological Predictors of Anxious Responding to the Threat of Ebola. Cognitive Therapy and Research 39:816-825. DOI: 10.1007/s10608-015-9701-9.

Van Bortel T, Basnayake A, Wurie F, Jambai M, Koroma AS, Muana AT, Hann K, Eaton J, Martin S, Nellums LB. 2016. Psychosocial effects of an Ebola outbreak at individual, community and international levels. Bull World Health Organ 94:210-214. DOI: 10.2471/BLT.15.158543.

Brooks SK, Webster RK, Smith LE, Woodland L, Wessely S, Greenberg N, Rubin GJ. 2020. The psychological impact of quarantine and how to reduce it: rapid review of the evidence. Lancet Publishing Group. DOI: 10.1016/S0140-6736(20)30460-8.

Brown KM, Hoye R, Nicholson M. 2012. Self-Esteem, Self-Efficacy, and Social Connectedness as Mediators of the Relationship Between Volunteering and Well-Being. Journal of Social Service Research 38:468-483. DOI: 10.1080/01488376.2012.687706.

Cacioppo JT, Ernst JM, Burleson MH, McClintock MK, Malarkey WB, Hawkley LC, Kowalewski RB, Paulsen A, Hobson JA, Hugdahl K. 2000. Lonely traits and concomitant physiological processes: The MacArthur social neuroscience studies. International Journal of Psychophysiology 35:143-154. 
529 Cacioppo JT, Hawkley LC, Thisted RA. 2010. Perceived social isolation makes me sad: 5-year 530 cross-lagged analyses of loneliness and depressive symptomatology in the chicago health, 531 aging, and social relations study. Psychology and Aging. DOI: 10.1037/a0017216.

532 Cacioppo JT, Hughes ME, Waite LJ, Hawkley LC, Thisted RA. 2006. Loneliness as a specific 533 risk factor for depressive symptoms: Cross-sectional and longitudinal analyses. Psychology and Aging. DOI: 10.1037/0882-7974.21.1.140.

Chin WW. 1998. Issues and opinion on structural equation modeling. MIS Quarterly: Management Information Systems.

Chu P Sen, Saucier DA, Hafner E. 2010. Meta-analysis of the relationships between social support and well-being in children and adolescents. Journal of Social and Clinical Psychology 29:624-645. DOI: 10.1521/jscp.2010.29.6.624.

Cole SW, Hawkley LC, Arevalo JM, Sung CY, Rose RM, Cacioppo JT. 2007. Social regulation of gene expression in human leukocytes. Genome biology 8:R189.

Deacon B, Olatunji BO. 2007. Specificity of disgust sensitivity in the prediction of behavioral avoidance in contamination fear. Behaviour Research and Therapy 45:2110-2120. DOI: 10.1016/j.brat.2007.03.008.

Diener E, Suh EM, Lucas RE, Smith HL. 1999. Subjective well-being: Three decades of progress. Psychological bulletin 125:276.

Drennan, J. (2003). Cognitive interviewing: verbal data in the design and pretesting of questionnaires. Journal of advanced nursing, 42(1), 57-63. 6:37. DOI: 10.1525/collabra.365. 
555 Fornell C, Larcker DF. 1981. Evaluating structural equation models with unobservable variables and measurement error. Journal of marketing research 18:39-50.

557

558

559

560

561

562

563

564

565

566

567

568

569

570

571

572

573

574

575

576

577

578

579

580

Gerhold L. 2020. COVID-19: Risk perception and Coping strategies. DOI: https://doi.org/10.31234/osf.io/xmpk4.

Gillison F, Standage M, Skevington S. 2008. Changes in quality of life and psychological need satisfaction following the transition to secondary school. British Journal of Educational Psychology 78:149-162. DOI: 10.1348/000709907X209863.

Groarke Id JM, Berry E, Graham-Wisener L, Mckenna-Plumley PE, Mcglinchey E, Armour C. 2020. Loneliness in the UK during the COVID-19 pandemic: Cross-sectional results from the COVID-19 Psychological Wellbeing Study. DOI: 10.1371/journal.pone.0239698.

Guo YR, Cao QD, Hong ZS, Tan YY, Chen SD, Jin HJ, Tan K Sen, Wang DY, Yan Y. 2020. The origin, transmission and clinical therapies on coronavirus disease 2019 (COVID-19) outbreak- An update on the status. Military Medical Research 7:11. DOI: 10.1186/s40779020-00240-0.

Hair Jr JF, Hult GTM, Ringle C, Sarstedt M. 2016. A primer on partial least squares structural equation modeling (PLS-SEM). Sage Publications.

Harper CA, Satchell LP, Fido D, Latzman RD. 2020. Functional Fear Predicts Public Health Compliance in the COVID-19 Pandemic. International Journal of Mental Health and Addiction:1-14. DOI: 10.1007/s11469-020-00281-5.

Hawkley LC, Cacioppo JT. 2010. Loneliness matters: A theoretical and empirical review of consequences and mechanisms. Annals of behavioral medicine 40:218-227.

Hellewell J, Abbott S, Gimma A, Bosse NI, Jarvis CI, Russell TW, Munday JD, Kucharski AJ, Edmunds WJ, Sun F, Flasche S, Quilty BJ, Davies N, Liu Y, Clifford S, Klepac P, Jit M, Diamond C, Gibbs H, van Zandvoort K, Funk S, Eggo RM. 2020. Feasibility of controlling COVID-19 outbreaks by isolation of cases and contacts. The Lancet Global Health 8:e488e496. DOI: 10.1016/S2214-109X(20)30074-7. 
581 Henseler J, Ringle CM, Sinkovics RRR. 2009. The use of partial least squares path modeling in

582 583 international marketing. In: Sinkovics RR, Ghauri PN eds. Advances in International Marketing. Bingley: Emerald Group Publishing, 277-320.

Hui DS, Joynt GM, Wong KT, Gomersall CD, Li TS, Antonio G, Ko FW, Chan MC, Chan DP, Tong MW, Rainer TH, Ahuja AT, Cockram CS, Sung JJY. 2005. Impact of severe acute respiratory syndrome (SARS) on pulmonary function, functional capacity and quality of life in a cohort of survivors. Thorax 60:401-409. DOI: 10.1136/thx.2004.030205.

Jaspal R, Nerlich B. 2020. Social representations, identity threat, and coping amid COVID-19. Jaspal, Rusi: School of Social Sciences, Nottingham Trent University, Nottingham, United Kingdom, NG1 4BU, rusi.jaspal@cantab.net: Educational Publishing Foundation. DOI: $10.1037 / \operatorname{tra} 0000773$.

Jose PE, Lim BTL. 2014. Social connectedness predicts lower loneliness and depressive symptoms over time in adolescents. Open Journal of Depression 03:154-163.

Kachanoff F, Bigman Y, Kapsaskis K, Gray K. 2020. Measuring Realistic and Symbolic Threats of COVID-19 and their Unique Impacts on Wellbeing and Adherence to Public Health Behaviors. PsyArXiv. DOI: doi.org/10.31234/osf.io/5zr3w.

Kanekar A, Sharma M. 2020. COVID-19 and Mental Well-Being: Guidance on the Application of Behavioral and Positive Well-Being Strategies. Healthcare 8:336. DOI: 10.3390/healthcare 8030336 .

Karwowski M, Zielińska A, Jankowska D, Strutyńska E, Omelańczuk I, Lebuda I. 2020. Creative Lockdown? A Daily Diary Study of Creative Activity During Pandemics. DOI: https://doi.org/10.31234/osf.io/kvesm.

Kock N. Full latent growth and its use in PLS-SEM: Testing moderating relationships.

Kock N. 2014. Advanced mediating effects tests , multi-group analyses , and measurement model assessments in PLS-based SEM. International Journal of e-Collaboration 10:1-13.

Kock N. 2020. WarpPLS 7.0 user manual. Laredo, TX: ScriptWarp Systems. 
607 Kock N, Gaskins L. 2014. The Mediating Role of Voice and Accountability in the Relationship 608 Between Internet Diffusion and Government Corruption in Latin America and Sub-Saharan 609 Africa. Information Technology for Development 20:23-43. DOI:

610 10.1080/02681102.2013.832129.

611 Kruithof WJ, Van Mierlo ML, Visser-Meily JMA, Van Heugten CM, Post MWM. 2013.

612 Associations between social support and stroke survivors' health-related quality of life-A $613 \quad$ systematic review. Patient Education and Counseling 93:169-176. DOI:

$614 \quad$ 10.1016/j.pec.2013.06.003.

615 Kuczynski AM, Kanter JW, Robinaugh DJ. 2020. Differential associations between interpersonal 616 variables and quality-of-life in a sample of college students. Quality of Life Research $617 \quad 29: 127-139$.

618 Lee RM, Robbins SB. 1995. Measuring belongingness: The social connectedness and the social 619 assurance scales. Journal of counseling psychology 42:232.

620 Leigh-Hunt N, Bagguley D, Bash K, Turner V, Turnbull S, Valtorta N, Caan W. 2017. An 621 overview of systematic reviews on the public health consequences of social isolation and 622 loneliness. Public Health 152:157-171.

623 Lim MH, Eres R, Vasan S. 2020. Understanding loneliness in the twenty-first century: an update 624 on correlates, risk factors, and potential solutions. Social Psychiatry and Psychiatric 625 Epidemiology 55:793-810. DOI: 10.1007/s00127-020-01889-7.

Luszczynska A, Pawlowska I, Cieslak R, Knoll N, Scholz U. 2013. Social support and quality of 627 life among lung cancer patients: a systematic review. Psycho-Oncology 22:2160-2168. 628 DOI: $10.1002 /$ pon.3218.

629 Ma ZF, Zhang Y, Luo X, Li X, Li Y, Liu S, Zhang Y. 2020. Increased stressful impact among 630 general population in mainland China amid the COVID-19 pandemic: A nationwide cross631 sectional study conducted after Wuhan city's travel ban was lifted. International Journal of 632 Social Psychiatry 66:770-779. DOI: 10.1177/0020764020935489.

633 MacKinnon DP, Krull JL, Lockwood CM. 2000. Equivalence of the mediation, confounding and 

suppression effect. Prevention Science 1:173-181. DOI: 10.1023/A:1026595011371.

635 Michalos AC. 2014. Encyclopedia of quality of life and well-being research. Springer 636 Netherlands Dordrecht.

637 Nitschke J, Forbes P, Ali N, Cutler J, Apps M, Lockwood P, Lamm C. 2020. Resilience During 638 Uncertainty. Greater Social Connectedness During COVID-19 Lockdown is Associated with Reduced Distress and Fatigue. :1-17. DOI: 10.31234/osf.io/9ehm7.

Organization WH. 1996. WHOQOL-BREF: introduction, administration, scoring and generic version of the assessment: field trial version, December 1996. World Health Organization.

Ozbay F, Johnson DC, Dimoulas E, Morgan CA, Charney D, Southwick S. 2007. Social support 643 644 and resilience to stress: from neurobiology to clinical practice. Psychiatry (Edgmont (Pa. :

Özmete E, Pak M. 2020. The Relationship between Anxiety Levels and Perceived Social Support during the Pandemic of COVID-19 in Turkey. Social Work in Public Health 35:603-616. DOI: $10.1080 / 19371918.2020 .1808144$.

Perkins AM, Corr PJ. 2014. Anxiety as an adaptive emotion. In: Parrott WG ed. The positive side of negative emotions. New York: The Guilford Press, 37-54.

Pressman SD, Cohen S, Barkin A, Miller GE, Rabin BS, Treanor JJ. 2005. Loneliness, social 651 652 network size, and immune response to influenza vaccination in college freshmen. Health Psychology. DOI: 10.1037/0278-6133.24.3.297.

Probst T, Budimir S, Pieh C. 2020. Depression in and after COVID-19 lockdown in Austria and 654 655 the role of stress and loneliness in lockdown: A longitudinal study. Journal of Affective Disorders 277:962-963. DOI: 10.1016/j.jad.2020.09.047.

Rachman S. 2004. Fear of contamination. Behaviour research and therapy 42:1227-1255. DOI: 10.1016/j.brat.2003.10.009. 
660 Reinartz W, Haenlein M, Henseler J. 2009. An empirical comparison of the efficacy of 661 662 covariance-based and variance-based SEM. International Journal of Research in Marketing 26:332-344. DOI: https://doi.org/10.1016/j.ijresmar.2009.08.001.

Reyes MES, Davis RD, Ann C, Chua PQ, Olaveria GL, Pamintuan LJE, Serrano MKB, Lou J, Tan EC. 2020. Relative Importance of Social Support and Social Connectedness as Protective Factors of Suicidal Ideation Among Selected Filipino Late Adolescents Relative Importance of Social Support and Social Connectedness as Protective Factors of Suicidal Ideation Am. Suicidology Online 11.

668

Rico-Uribe LA, Caballero FF, Martín-María N, Cabello M, Ayuso-Mateos JL, Miret M. 2018. Association of loneliness with all-cause mortality: A meta-analysis. PloS one 13.

Russell DW. 1996. UCLA Loneliness Scale (Version 3): Reliability, validity, and factor structure. Journal of personality assessment 66:20-40.

Sajadi SA, Ebadi A, Moradian ST. 2017. Quality of life among family caregivers of patients on hemodialysis and its relevant factors: A systematic review. International Journal of Community Based Nursing and Midwifery 5:206-218.

Satici B, Gocet-Tekin E, Deniz ME, Satici SA. 2020a. Adaptation of the Fear of COVID-19 Scale: Its association with psychological distress and life satisfaction in Turkey. International Journal of Mental Health and Addiction.

Satici B, Saricali M, Satici SA, Griffiths MD. 2020b. Intolerance of Uncertainty and Mental Well-being: Serial Mediation by Rumination and Fear of COVID-19. International Journal of Mental Health and Addiction. DOI: 10.1007/s11469-020-00305-0.

Sherbourne CD, Stewart AL. 1991. The MOS social support survey. Social science \& medicine 682 $32: 705-714$.

683

Stephan WG, Ybarra O, Morrison KR. 2009. Intergroup threat theory. In: Nelson T ed. Handbook of Prejudice. Mahwah, NJ: Lawrence Erlbaum, 43-59. 
685 Tajfel H, Turner JC. 1979. An integrative theory of intergroup conflict. In: Worchel WG, Austin 686 S eds. The social psychology of intergroup relations. Monterey, CA: Brooks/Cole, 33-47.

687 Tenenhaus M, Esposito Vinzi V, Chatelin YM, Lauro C. 2005. PLS Path Modeling 688 Computational Statistics \& Data Analysis, 48.

689 Vafaei H, Roozmeh S, Hessami K, Kasraeian M, Asadi N, Faraji A, Bazrafshan K, Saadati N, 690 Aski SK, Zarean E, Golshahi M, Haghiri M, Abdi N, Tabrizi R, Heshmati B, Arshadi E. 691 2020. Obstetrics healthcare providers' mental health and quality of life during covid-19 692 pandemic: Multicenter study from eight cities in Iran. Psychology Research and Behavior 693 Management 13:563-571. DOI: 10.2147/PRBM.S256780.

694 Valtorta N, Hanratty B. 2012. Loneliness, isolation and the health of older adults: Do we need a 695 new research agenda? Journal of the Royal Society of Medicine, Supplement 105:518-522. DOI: $10.1258 /$ jrsm.2012.120128.

Verger P, Combes J-B, Kovess-Masfety V, Choquet M, Guagliardo V, Rouillon F, Peretti-Wattel

698

699

700

701

Wang C, Pan R, Wan X, Tan Y, Xu L, Ho CS, Ho RC. 2020. Immediate Psychological

702

703

704 P. 2009. Psychological distress in first year university students: socioeconomic and academic stressors, mastery and social support in young men and women. Social psychiatry and psychiatric epidemiology 44:643-650.

705

706

707

708

709

710

711 Responses and Associated Factors during the Initial Stage of the 2019 Coronavirus Disease (COVID-19) Epidemic among the General Population in China. International Journal of Environmental Research and Public Health 17:1729. DOI: 10.3390/ijerph17051729.

Warner LM, Gutiérrez-Doña B, Villegas Angulo M, Schwarzer R. 2015. Resource loss, selfefficacy, and family support predict posttraumatic stress symptoms: a 3-year study of earthquake survivors. Anxiety, Stress, \& Coping 28:239-253.

Wetzels M, Odekerken-Schröder G, Van Oppen C. 2009. Using PLS path modeling for assessing hierarchical construct models: Guidelines and empirical illustration. MIS Quarterly: Management Information Systems 33:177-195. DOI: 10.2307/20650284.

Wheaton MG, Abramowitz JS, Berman NC, Fabricant LE, Olatunji BO. 2012. Psychological 
712 predictors of anxiety in response to the H1N1 (swine flu) pandemic. Cognitive Therapy and 713 Research 36:210-218.

714 Willaby HW, Costa DSJ, Burns BD, MacCann C, Roberts RD. 2015. Testing complex models

715 with small sample sizes: A historical overview and empirical demonstration of what Partial

716 Least Squares (PLS) can offer differential psychology. Personality and Individual

717 Differences 84:73-78. DOI: https://doi.org/10.1016/j.paid.2014.09.008.

$718 \mathrm{Xu}$ J, Ou L. 2014. Resilience and quality of life among Wenchuan earthquake survivors: the 719 mediating role of social support. Public health 128:430-437.

720 Zhang Y, Ma ZF. 2020. Psychological responses and lifestyle changes among pregnant women 721 with respect to the early stages of COVID-19 pandemic. International Journal of Social $722 \quad$ Psychiatry. DOI: 10.1177/0020764020952116.

723 Zhang Y, Ma Z. 2020. Impact of the COVID-19 pandemic on mental health and quality of life 724 among local residents in Liaoning Province, China: A cross-sectional study. International 725 Journal of Environmental Research and Public Health [revista en Internet] 2020 [acceso 8 726 de octu.

727 Zinbarg RE, Revelle W, Yovel I, Li W. 2005. Cronbach's, $\alpha$ Revelle's $\beta$ and McDonald's $\omega$ H:

728 Their relations with each other and two alternative conceptualizations of reliability.

729 Psychometrika 70:123-133. DOI: 10.1007/s11336-003-0974-7. 
Figure 1

The hypothesized Structural Equation Model

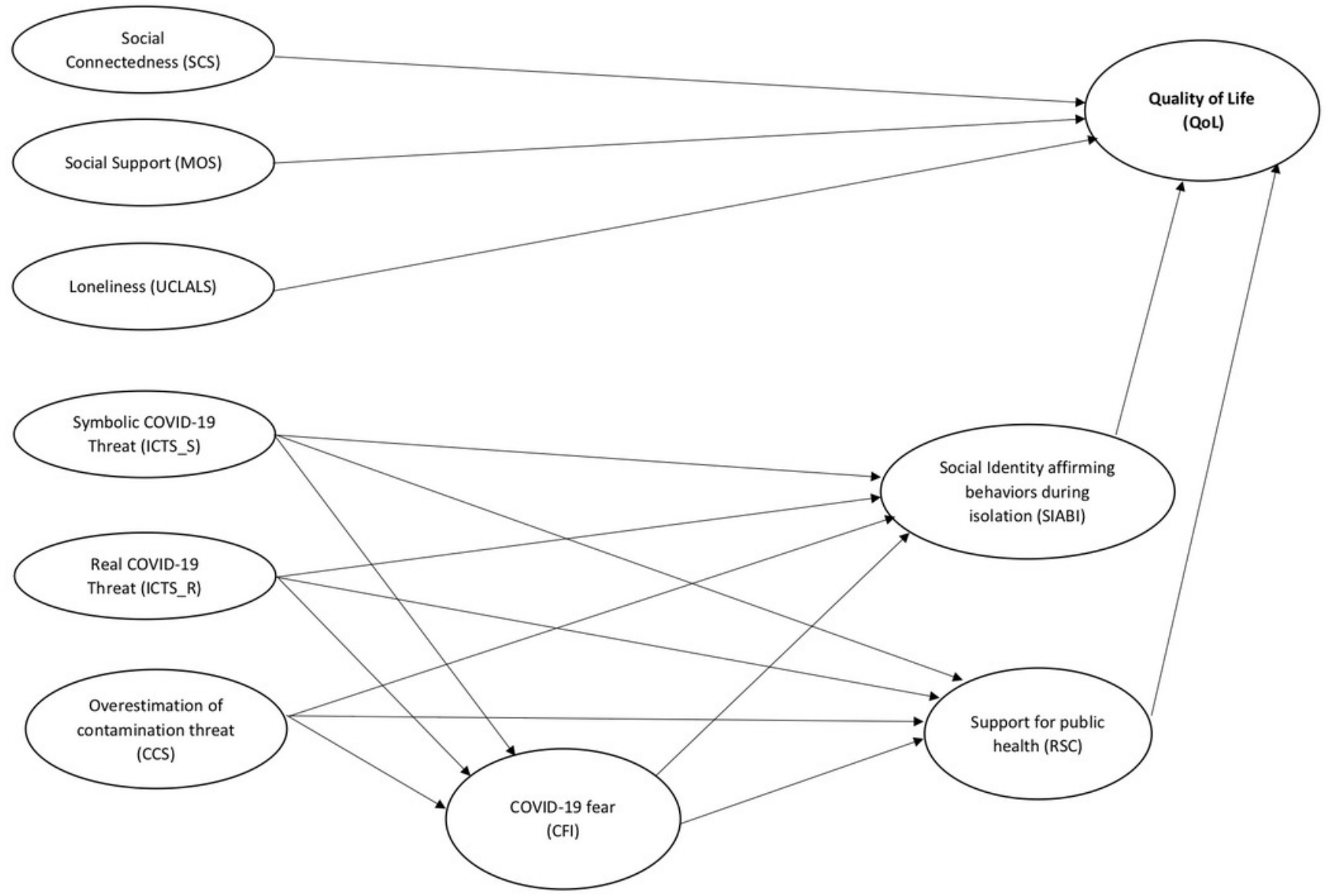


Figure 2

Results of the structural equation model for the proposed model

Paths freely estimated in the analysis but not depicted in diagram: ICTS_S $\rightarrow$ SIABI $(\beta=.224$, $p=<.001) ;$ ICTS_R $\rightarrow \operatorname{SIABI}(\beta=.063, p=.178) ; \mathrm{CCS} \rightarrow \operatorname{SIABI}(\beta=.114, p=.046) ;$ ICTS_S $\rightarrow$ $\operatorname{RSC}(\beta=-.249, p<.001) ;$ ICTS_R $R \rightarrow \operatorname{RSC}(\beta=.248, p<.001) ; \operatorname{CCS} \rightarrow \operatorname{RSC}(\beta=.030, p=$ .328). Moreover, the direct effects of QoL predictors on $\mathrm{CFI}$, and the CFI predictors on QoL showed not significant effects. Dashed lines indicate paths that were not statistically significant $(p>.05)$ in the analysis. ${ }^{* * *} p<.001 ;{ }^{* *} p<.01 ; * p<.05$

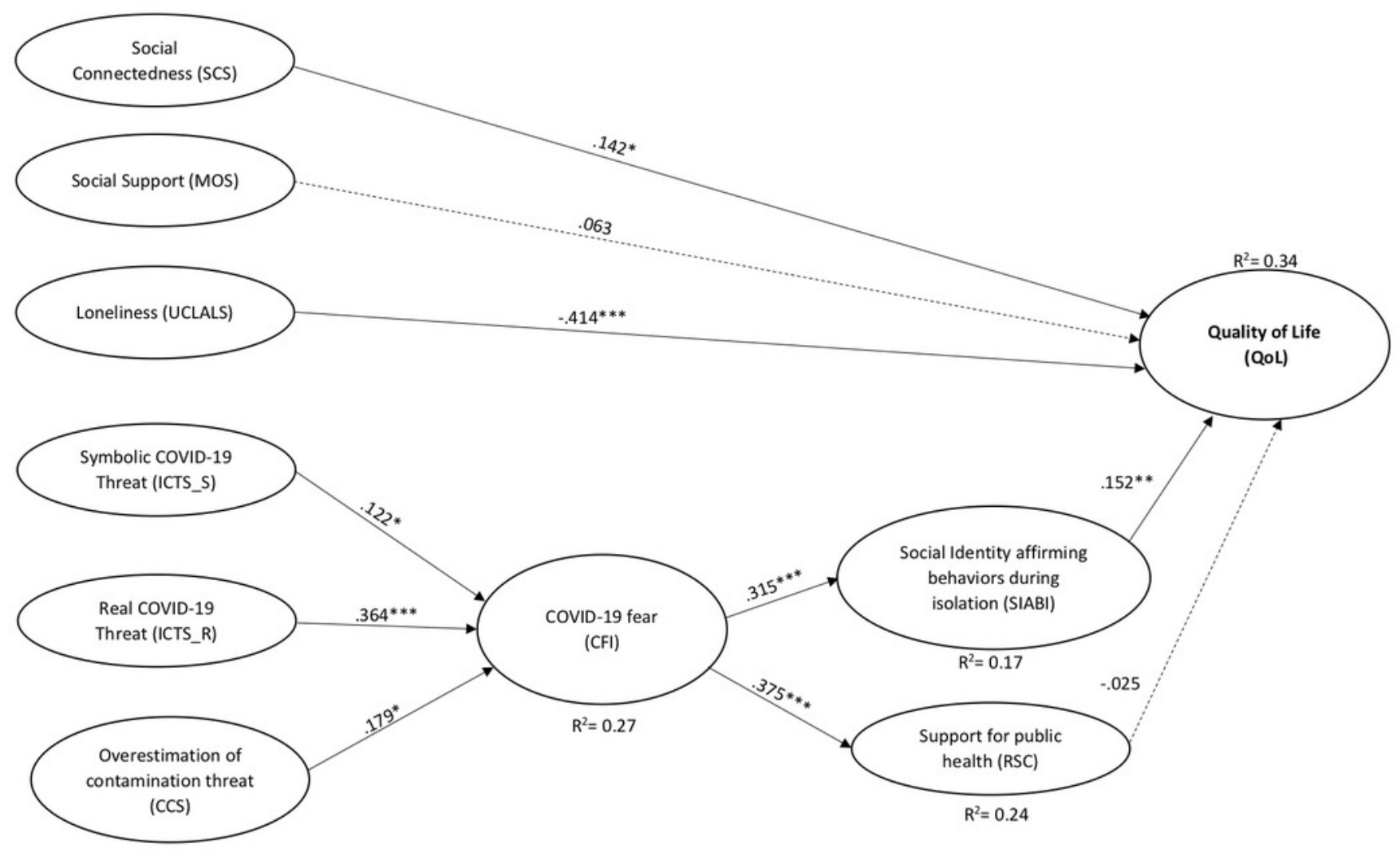




\section{Table $\mathbf{1}$ (on next page)}

Summary of Hypothesized effects in the tested model

SCS = Perceived social connectedness; MOS = social support; UCLALS = loneliness; ICTS_S = Symbolic COVID-19 threat; ICTS_R = Realistic COVID-19 threat; CCS = Overestimation of threat from potentially contaminated objects; CFI = COVID-19 fear inventory; SIABI = Social identity during isolation; RSC = Support for public health initiatives to reduce spread of COVID-19 scale; QoL = Quality of life. 


\section{PeerJ}

\begin{tabular}{|c|c|c|c|c|}
\hline \multicolumn{2}{|r|}{ Peeru } & \multicolumn{3}{|c|}{ Manuscriptto_be_revie } \\
\hline Hypothesis & Independent variable & Dependent variable & Mediator (s) & Prediction \\
\hline $\mathrm{H}_{1 \mathrm{a}}$ & SCS & QoL & - & Effect $(+)$ \\
\hline $\mathrm{H}_{1 \mathrm{~b}}$ & MOS & QoL & - & Effect $(+)$ \\
\hline $\mathrm{H}_{1 \mathrm{c}}$ & UCLALS & QoL & - & Effect (-) \\
\hline $\mathrm{H}_{2 \mathrm{a}}$ & ICTS S & CFI & - & Effect $(+)$ \\
\hline $\mathrm{H}_{2 \mathrm{~b}}$ & ICTS_R & CFI & - & Effect $(+)$ \\
\hline $\mathrm{H}_{2 \mathrm{c}}$ & $\mathrm{CCS}^{-}$ & CFI & - & Effect $(+)$ \\
\hline $\mathrm{H}_{3 \mathrm{a}}$ & CFI & SIABI & - & Effect $(+)$ \\
\hline $\mathrm{H}_{3 \mathrm{~b}}$ & CFI & $\mathrm{RSC}$ & - & Effect $(+)$ \\
\hline $\mathrm{H}_{4 \mathrm{a}}$ & SIABI & QoL & - & Effect $(+)$ \\
\hline $\mathrm{H}_{4 \mathrm{~b}}$ & $\mathrm{RSC}$ & QoL & - & Effect $(+)$ \\
\hline $\mathrm{H}_{5 \mathrm{a}}$ & ICTS_S & SIABI & - & Effect $(+)$ \\
\hline $\mathrm{H}_{5 \mathrm{~b}}$ & ICTS_R & SIABI & - & Effect $(+)$ \\
\hline $\mathrm{H}_{5 \mathrm{c}}$ & $\mathrm{CCS}^{-}$ & SIABI & - & Effect $(+)$ \\
\hline $\mathrm{H}_{6 \mathrm{a}}$ & ICTS_S & $\mathrm{RSC}$ & - & Effect (-) \\
\hline $\mathrm{H}_{6 \mathrm{~b}}$ & ICTS_R & $\mathrm{RSC}$ & - & Effect $(+)$ \\
\hline $\mathrm{H}_{6 \mathrm{c}}$ & $\mathrm{CCS}^{-}$ & $\mathrm{RSC}$ & - & Effect $(+)$ \\
\hline $\mathrm{H}_{7 \mathrm{a}}$ & ICTS_S & SIABI & CFI & Effect $(+)$ \\
\hline $\mathrm{H}_{7 \mathrm{~b}}$ & ICTS_R & SIABI & CFI & Effect $(+)$ \\
\hline $\mathrm{H}_{7 \mathrm{c}}$ & $\mathrm{CCS}^{-}$ & SIABI & CFI & Effect $(+)$ \\
\hline $\mathrm{H}_{8 \mathrm{a}}$ & ICTS_S & RSC & CFI & Effect $(+)$ \\
\hline $\mathrm{H}_{8 \mathrm{~b}}$ & ICTS_R & $\mathrm{RSC}$ & CFI & Effect $(+)$ \\
\hline $\mathrm{H}_{8 \mathrm{c}}$ & $\mathrm{CCS}^{-}$ & RSC & CFI & Effect $(+)$ \\
\hline
\end{tabular}

1 


\section{Table 2 (on next page)}

Sociodemographic characteristics and COVID-19 related information of the sample

$\mathrm{N}=$ Number 


\begin{tabular}{|c|c|}
\hline & Percentual $(\%)$ \\
\hline \multicolumn{2}{|l|}{ Students } \\
\hline Yes & 83.6 \\
\hline No & 16.4 \\
\hline \multicolumn{2}{|l|}{ School } \\
\hline University & 84.6 \\
\hline High school & 15.4 \\
\hline \multicolumn{2}{|l|}{ Working } \\
\hline Yes & 38.4 \\
\hline No & 61.6 \\
\hline \multicolumn{2}{|l|}{ Work } \\
\hline Freelance & 18.1 \\
\hline Employee & 16.9 \\
\hline Occasional & 38.6 \\
\hline Other & 26.5 \\
\hline \multicolumn{2}{|l|}{ Lockdown region } \\
\hline Abruzzo & 0.9 \\
\hline Basilicata & 0.5 \\
\hline Calabria & 2.3 \\
\hline Campania & 84.0 \\
\hline Friuli-Venezia Giulia & 0.5 \\
\hline Lazio & 11.0 \\
\hline Marche & 0.5 \\
\hline Missing value & 0.5 \\
\hline \multicolumn{2}{|c|}{ Acquaintances/friends infected } \\
\hline Yes & 19.2 \\
\hline No & 80.8 \\
\hline \multicolumn{2}{|c|}{$\mathrm{N}$ of acquaintances/ friends infected } \\
\hline 1 & 9.6 \\
\hline 2 & 6.4 \\
\hline$>2$ & 2.8 \\
\hline \multicolumn{2}{|l|}{ Family members infected } \\
\hline Yes & 3.2 \\
\hline No & 96.8 \\
\hline \multicolumn{2}{|c|}{$\mathrm{N}$ of family members infected } \\
\hline 1 & 1.4 \\
\hline 2 & 0.9 \\
\hline$>2$ & 1 \\
\hline
\end{tabular}




\section{Table 3 (on next page)}

Average Variances Extracted, Validity indices and Correlations Among Latent Variables

$\mathrm{AVE}=$ average variance extracted; $\mathrm{AVEs}=$ square root of average variances extracted; $\alpha=$ Cronbach alpha coefficient; correlation coefficients presented below the principal diagonal, pvalues presented above the principal diagonal; composite reliability coefficients $(\rho)$ are presented on the principal diagonal; SCS = Perceived social connectedness; $\mathrm{MOS}=$ social support; UCLALS = loneliness; ICTS_S = Symbolic COVID-19 threat; ICTS_R = Realistic COVID-19 threat; CCS = Overestimation of threat from potentially contaminated objects; CFI $=$ Fear for COVID-19; SIABI = Social identity during isolation; RSC = Support for public health initiatives to reduce spread of COVID-19 scale; QoL = Quality of life. 


\begin{tabular}{lccccccccccccc}
\hline & AVE & AVEs & $\boldsymbol{\alpha}$ & $\mathbf{1}$ & $\mathbf{2}$ & $\mathbf{3}$ & $\mathbf{4}$ & $\mathbf{5}$ & $\mathbf{6}$ & $\mathbf{7}$ & $\mathbf{8}$ & $\mathbf{9}$ & $\mathbf{1 0}$ \\
\hline 1. SCS & .588 & .767 & .899 & .919 & $<.001$ & $<.001$ & .200 & .328 & .237 & .806 & .353 & $<.001$ & $<.001$ \\
2. MOS & .581 & .762 & .959 & -.399 & .963 & $<.001$ & .941 & $<.001$ & .696 & .030 & .001 & .003 & $<.001$ \\
3. UCL_ALS & .465 & .682 & .869 & .667 & -.523 & .895 & .765 & .440 & .633 & .264 & .116 & .025 & $<.001$ \\
4. ICTS_S & .537 & .733 & .783 & .088 & -.055 & -.021 & .852 & $<.001$ & .088 & .001 & $<.001$ & .071 & .893 \\
5. ICTS_R & .596 & .772 & .773 & -.067 & .250 & -.053 & .290 & .855 & .016 & $<.001$ & .002 & $<.001$ & .868 \\
6. CCS & .445 & .667 & .947 & .081 & .027 & .033 & .117 & .165 & .953 & .003 & .008 & .081 & .614 \\
7. CFI & .349 & .591 & .678 & -.017 & .148 & -.077 & .220 & .371 & .204 & .783 & $<.001$ & $<.001$ & .088 \\
8. SIABI & .482 & .694 & .730 & -.064 & .222 & -.108 & .259 & .210 & .181 & .297 & .823 & .013 & .015 \\
9. RSC & .502 & .709 & .657 & -.236 & .206 & -.154 & -.124 & .317 & .120 & .374 & .171 & .788 & .221 \\
10. QoL & .596 & .772 & .774 & -.418 & .266 & -.515 & -.009 & -.011 & .035 & .117 & .166 & .084 & .855 \\
\hline
\end{tabular}

1 


\section{Table 4 (on next page)}

Controlling for the direct effects of QoL and CFI predictors

CFI = Fear for COVID-19; QoL = Quality of life; SCS = Perceived social connectedness; MOS = social support; UCLALS = loneliness; ICTS_S $=$ Symbolic COVID-19 threat; ICTS_R $=$ Realistic COVID-19 threat; CCS = Overestimation of threat from potentially contaminated objects; $\mathrm{SIABI}=$ Social identity during isolation; $\mathrm{RSC}=$ Support for public health initiatives to reduce spread of COVID-19 scale. 


\begin{tabular}{lccc}
\hline Direct effects of QoL predictors on CAI & & $\boldsymbol{\beta}$ \\
\hline SCS & $\rightarrow$ & CFI & .031 \\
MOS & $\rightarrow$ & CFI & .089 \\
UCLALS & $\rightarrow$ & CFI & -.087 \\
\hline Direct effects of CAI predictors on QoL & & $\boldsymbol{\beta}$ \\
\hline ICTS_S & $\rightarrow$ & QoL & -.043 \\
ICTS_R & $\rightarrow$ & QoL & -.058 \\
CCS & $\rightarrow$ & QoL & .037 \\
\hline
\end{tabular}

1 